\title{
SINGLE INCISION LAPAROSCOPIC SURGERY: USE OF CONVENTIONAL LAPAROSCOPIC INSTRUMENTS IN SINGLE INCISION LAPAROSCOPIC SURGERY: OUR EXPERIENCE
}

\author{
Haridarshan Sira Janardhan1, Shreyamsa Manjunath ${ }^{2}$
}

${ }_{1}^{1}$ Assistant Professor, Department of General Surgery, Rajarajeshwari Medical College and Hospital, Bangalore. ${ }_{2}^{2}$ Assistant Professor, Department of General Surgery, Rajarajeshwari Medical College and Hospital, Bangalore.

\begin{tabular}{l}
\hline ABSTRACT \\
BACKGROUND \\
Laparoscopic surgery has undergone several modifications since its advent. There has been a shift from a standard multiport \\
approach to more minimalistic approaches. SILS is a major step in this evolutionary process. We present our experience with SILS \\
using conventional laparoscopic instruments and without the need for a SILS port.
\end{tabular}

\section{METHODS}

211 patients in Fortis Hospitals, Bangalore, India, who underwent SILS for various abdominal conditions from May 2009 to May 2011 were included in the study. Variables such as operating time, conversion to multi-port laparoscopy or open surgery, complications, analgesia requirements and hospital stay were included.

\section{RESULTS}

211 patients underwent SILS using conventional laparoscopic instruments for Gallstones, Appendicitis, Morbid Obesity, Gynaecological conditions and Renal cysts. Average age group was 48.5 years; mean duration of hospital stay was 46.5 hours; 166 Laparoscopic cholecystectomies were done, out of which 47 were acute cholecystitis. There were no cases converted to open surgeries.

\section{CONCLUSION}

Single Incision Laparoscopic surgery is technically feasible and as effective as conventional laparoscopic surgery. It is a safe procedure and provides an advantage with regards to analgesia requirement, length of hospital stay and early return to work. Cosmetically, it is superior to multiport laparoscopy.

\section{KEYWORDS}

Single Incision, Conventional Instruments, Cosmesis, Cost Effective.

HOW TO CITE THIS ARTICLE: Janardhan HS, Manjunath S. Single incision laparoscopic surgery: use of conventional laparoscopic instruments in single incision laparoscopic surgery: our experience. J. Evolution Med. Dent. Sci. 2016;5(34):1881-1884,

DOI: $10.14260 /$ jemds/2016/444

\section{INTRODUCTION}

Since its advent, laparoscopy has rapidly become the standard of care for a wide variety of abdominal surgeries offering the advantages of decreased post-operative pain, early recovery, shorter duration of hospital stay, early return to work and improved cosmesis. The past few years have seen a further push towards more minimalistic approaches to abdominal surgery. Single incision laparoscopic surgery has been the logical next step in this minimalistic approach. It has been shown to be cosmetically superior to conventional laparoscopic surgery with the further advantages of decreased post-operative pain and requirement for analgesics leading to a quicker recovery as compared to conventional laparoscopic surgery.

\section{OBJECTIVE}

Our experience with SILS using conventional laparoscopic instruments and a brief discussion on review of literature.

\section{DESIGN}

Retrospective observational study.

Financial or Other, Competing Interest: None

Submission 29-02-2016, Peer Review 08-04-2016,

Acceptance 12-04-2016, Published 26-04-2016.

Corresponding Author

Dr. Haridarshan Sira Janardhan,

76-1-1, VR Layout, 1st Phase,

J. P. Nagar, Bangalore-560078.

E-mail: sjharidarshan@gmail.com

DOI: $10.14260 /$ jemds/2016/444

\section{METHODS}

211 patients at the Fortis Hospitals, Bangalore, India, underwent SILS by a single surgeon from May 2009 to May 2011. Variables such as operating time, conversion to multiport laparoscopy or open surgery, complications, analgesia requirements and hospital stay were taken into account. Patients were followed up for a period of 3 months. Paediatric age groups were excluded.

\section{Surgical Technique}

All the patients were given General Anaesthesia. Patient was positioned on the table depending on the type of surgery. Intraperitoneal access was achieved by the open technique. A single $20 \mathrm{~mm}$ periumbilical curvilinear incision was made either above, below or to its left depending on the proposed operative procedure. Incision was deepened to linea alba. Fascial incision was made, peritoneal cavity was opened by blunt technique and a $10 \mathrm{~mm}$ blunt trocar was deployed. Pneumoperitoneum was created with carbon dioxide insufflation at a pressure of $14 \mathrm{mmHg}$. The secondary trocars were inserted above and lateral to the $10 \mathrm{~mm}$ trocar with an oblique path ( $\mathrm{Z}$ technique).

\section{RESULTS}

All the patients underwent SILS using conventional laparoscopic instruments via a single periumbilical incision using conventional laparoscopic trocars and instruments. 
Average age group was 48.5 years; mean operative time (For all cases done) was 112.5 (15 min-210 min), the operating time being the longest for Sleeve gastrectomy ( $210 \mathrm{~min}$ ) and the mean duration of hospital stay was 46.5 hours, (21-72 hours). There were no intraoperative or immediate postoperative complications noted. There were nine cases of cholecystectomies that were converted to multiport [5.42\%] due to large gallbladder $[n=4]$, dense adhesions $[n=3]$ and empyematous gallbladder $[\mathrm{n}=2]$. The patients were followed up for 3 months, assessed clinically and no complications were noted in this period. There was no incidence of port site hernia and port site infections.

One patient had a combined ectopic pregnancy excision with tubal ligation, one patient had a combined cholecystectomy with appendectomy and two patients had a combined cholecystectomy with ovarian cystectomy; 47 patients out of 166 who underwent SILS cholecystectomy were diagnosed with acute cholecystitis; 9 cases out of 47 cases of acute cholecystitis were converted to multi-port laparoscopic surgery. There were no cases converted to open surgeries. Among patients who underwent sleeve gastrectomy, one had BMI of 44.9 and the other had BMI of 37.8.

"Table 1 shows the number of patients included in the study and also shows the total number of male patients and female patients in the study."

\begin{tabular}{|c|c|c|}
\hline Total No. of Patients & Males & Females \\
\hline 211 & 78 & 133 \\
\hline \multicolumn{3}{|c|}{ Table 1 } \\
\hline
\end{tabular}

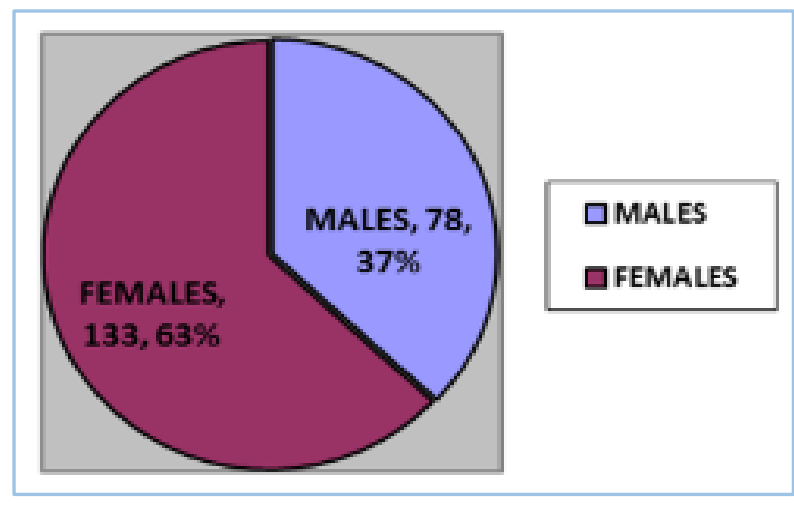

Fig. 1: Sex Distribution
"Table 2 shows the number of parameters that have been considered for the study and also shows the different results and interpretations of the individual parameters."

\begin{tabular}{|c|c|}
\hline Parameters & $\begin{array}{l}\text { Statistics } \\
\end{array}$ \\
\hline Age Group & 21-76 (mean 48.5 years) \\
\hline BMI & 17.1-55 (mean 36.05) \\
\hline Mean Operating Time & 15 to 210 min (mean 112.5 ) \\
\hline Duration of Stay & 21 to 72 hours (mean 46.5 ) \\
\hline $\begin{array}{c}\text { Post-Op Analgesia } \\
\text { [Diclofenac/Aceclofenac } \\
\text { and/or Paracetamol] }\end{array}$ & 3 Days \\
\hline Visual Analogue Scale for Pain & 1-4 (mean 2.5) \\
\hline Return to Normal Activity & 3-5 Days (mean 4 days) \\
\hline $\begin{array}{l}\text { Conversion (Multi- } \\
\text { port/Laparotomy) }\end{array}$ & $\begin{array}{l}9 \text { (Multiport) cases of Acute } \\
\text { cholecystitis (Large } \\
\text { gallbladder }[\mathrm{n}=4] \text {, dense } \\
\text { adhesions }[\mathrm{n}=3] \text { and } \\
\text { empyematous gallbladder } \\
{[\mathrm{n}=2] \text { ) }}\end{array}$ \\
\hline Complications & 0 \\
\hline \multicolumn{2}{|c|}{ Table 2} \\
\hline
\end{tabular}

"Table 3 shows the different types of surgeries performed by Single Incision Laparoscopic Surgery (SILS) using conventional laparoscopic instruments and the number of surgeries performed."

\begin{tabular}{|c|c|}
\hline Types of Surgeries & Number of Cases \\
\hline Cholecystectomy & 166 \\
\hline Appendectomy & 26 \\
\hline Tubal Ligation & 4 \\
\hline Ovarian Cystectomy & 4 \\
\hline Ectopic Pregnancy & 3 \\
\hline Sleeve Gastrectomy & 4 \\
\hline Renal Cyst Excision & 2 \\
\hline Hysterectomy & 1 \\
\hline Lymph Node Biopsy & 4 \\
\hline Splenic Cyst Excision & 1 \\
\hline \multicolumn{2}{|c|}{ Table 3 } \\
\hline
\end{tabular}

"Table 4 shows the comparison of our study with the studies done by other authors considering the number of cases, conversion to standard laparoscopy, complications and the duration of the surgery."

\begin{tabular}{|c|c|c|c|c|c|}
\hline Authors & $\begin{array}{c}\text { Publication } \\
\text { Year }\end{array}$ & $\mathbf{n}$ & $\begin{array}{c}\text { Conversion to Standard } \\
\text { Laparoscopy (\%) }\end{array}$ & $\begin{array}{c}\text { Complication } \\
(\%)\end{array}$ & $\begin{array}{c}\text { Average Operating } \\
\text { Time (min) }\end{array}$ \\
\hline Palanivelu et al[1] & 2008 & 10 & $4(40)$ & $1(10)$ & 148 \\
\hline Navarra et al[2] & 2008 & 30 & 0 & 0 & 123 \\
\hline Cugura et al[3] & 2008 & 1 & 0 & 0 & $\mathrm{NR}$ \\
\hline Bucher et al[4] & 2009 & 11 & 0 & 0 & 52 \\
\hline Ersin et al[5] & 2009 & 20 & $1(5)$ & 0 & 94 \\
\hline Nguyen et al[6] & 2009 & 1 & 0 & 0 & 70 \\
\hline Langwieler et al[7] & 2009 & 14 & 0 & 0 & $53-115$ \\
\hline Podolsky et al[8] & 2009 & 5 & 0 & 0 & 121 \\
\hline Zhu et al[9] & 2009 & 26 & 0 & 0 & 62 \\
\hline Guo et al[10] & 2008 & 1 & 0 & 0 & 158 \\
\hline Gumbs et al[11] & 2009 & 2 & 0 & 0 & $<60$ \\
\hline Hong et al[12] & 2009 & 15 & 0 & 0 & 79 \\
\hline Kuon Lee et al[13] & 2009 & 37 & $5(13.5)$ & $2(5.4)$ & 83.6 \\
\hline Our cases & 2010-11 & 211 & $9(5.42)$ & 0 & $15-210$ \\
\hline
\end{tabular}




\section{DISCUSSION}

Philip Mouret performed the first laparoscopic cholecystectomy in 1987, which was later established in 1990 by Dubois and Perissat. ${ }^{14}$ Since then, it has been accepted worldwide and is now considered as a Gold standard procedure in the surgical treatment of gall bladder diseases. ${ }^{15}$ Standard laparoscopic cholecystectomy is performed using the conventional four port technique. The fourth lateral port is created in order to expose the Calot's triangle by holding and retracting the fundus of the gall bladder. However, with growing laparoscopic experience, additional ports may not be necessary and the surgery can be safely performed with a single incision. ${ }^{16}$ SILS was described as early as 1992 by Pelosi et al, who performed a single-puncture laparoscopic appendectomy. ${ }^{17}$ Further, in the era of laparoscopic surgery, less post-operative pain and early recovery are major goals to achieve better patient care and cost effectiveness. Several studies have demonstrated that less postoperative pain is associated with a reduction in either size or number of ports. ${ }^{18}$

Single incision laparoscopic surgery is performed through one incision usually at the umbilicus. This approach limits the port incisions to one site. Positioning the single access within the umbilicus results in better cosmesis and avoids penetration through the muscle. Reducing the abdominal wall trauma results in less postoperative pain, faster recovery, fewer wound complications and improved cosmetic outcomes. Risk of epigastric vessel injury can be eliminated by avoiding the lateral placement of ports. Access through the umbilicus reduces the torching effect of trocars facilitating the mobility of the instruments/trocars in different directions. There are ports, disposable hand instruments and flexible endoscopes that have been suggested to do this surgery, but they are expensive and would increase the cost of the operation. ${ }^{19}$ Single incision laparoscopic surgery is gaining popularity as a complement to standard laparoscopic surgery with regards to cosmesis, less pain, shorter duration of hospital stays and early recovery. ${ }^{20}$

With our experience, these additional instruments are not required as equal efficacy and success rate can be achieved with conventional laparoscopic instruments, ports and telescopes. We have performed SILS using conventional laparoscopic instruments in over 200 patients by triangular port insertion. Safety was defined as performance of the procedure without any major complications like bleeding and injury to the bile duct, major vessels or any viscera. Benefits were measured in terms of operative time, days of hospital stay, postoperative recovery time after discharge, days taken to return to work, quantitative requirement of analgesia after surgery, assessment of postoperative pain score using a $10-\mathrm{cm}$ unscaled Visual Analogue Score (VAS) and cosmesis with a 3month follow-up period.

As per Table 4, our study was compared with studies of different authors. Our study showed a conversion percentage of 5.42 as compared to the studies done by Palanivelu et al ${ }^{1}$ (40\%), Ersin et $\mathrm{al}^{5}$ (5\%) and by Kuon Lee et $\mathrm{al}^{13}$ (13.5\%).

Our study had no complications as compared to the studies done by Palanivelu et $\mathrm{al}^{1}(10 \%)$ and by Kuon Lee et $\mathrm{al}^{13}$ $(5.4 \%)$. Average operating time in our study is comparable to other studies as shown in Table 4.

\section{CONCLUSION}

In our experience, SILS using conventional laparoscopic instruments is equally safe and effective as compared to the conventional laparoscopic surgeries or SILS with custom made instruments. SILS with conventional laparoscopic instruments is superior in terms of cost effectiveness. With increasing experience and expertise, SILS can be offered to a majority of patients mandating laparoscopic solutions of benign abdominal pathologies. SILS can also be applied to the treatment of acute cholecystitis and difficult gallbladders as safely as conventional multiport laparoscopy.

\section{REFERENCES}

1 Palanivelu C, Rajan PS, Rangarajan $M$, et al. Transumbilical flexible endoscopic cholecystectomy in humans: first feasibility study using a hybrid technique. Endoscopy 2008;40(5):428-31.

2 Navarra G, La Malfa G, Bartolotta G, et al. The invisible cholecystectomy: a different way. Surg Endosc 2008;22(9):2103.

3 Cugura JF, Janković J, Kulis T, et al. Single incision laparoscopic surgery (SILS) cholecystectomy: where are we? Acta Clin Croat 2008;47(4):245-8.

4 Bucher P, Pugin F, Buchs N, et al. Single port access laparoscopic cholecystectomy (with video). World J Surg 2009;33(5):1015-9.

5 Ersin S, Firat O, Sozbilen M. Single-incision laparoscopic cholecystectomy: is it more than a challenge? Surg Endosc 2010;24(1):68-71.

6 Nguyen NT, Reavis KM, Hinojosa MW, et al. Laparoscopic transumbilical cholecystectomy without visible abdominal scars. J Gastrointest Surg 2009;13(6):1125-8.

7 Langwieler TE, Nimmesgern T, Back M. Single-port access in laparoscopic cholecystectomy. Surg Endosc 2009;23(5):1138-41.

8 Podolsky ER, Rottman SJ, Poblete H, et al. Single port access (SPA) cholecystectomy: a completely transumbilical approach. J Laparoendosc Adv Surg Tech A 2009;19(2):219-22.

9 Zhu JF, Hu H, Ma YZ, et al. Transumbilical endoscopic surgery: a preliminary clinical report. Surg Endosc 2009;23(4):813-7.

10 Guo W, Zhang ZT, Han W, et al. Transumbilical single-port laparoscopic cholecystectomy: a case report. Chin Med J (Engl) 2008;121(23):2463-4.

11 Gumbs AA, Milone L, Sinha P, et al. Totally transumbilical laparoscopic cholecystectomy. J Gastrointest Surg 2009;13(3):533-4.

12 Hong TH, You YK, Lee KH. Transumbilical single-port laparoscopic cholecystectomy: scarless cholecystectomy. Surg Endosc 2009;23(6):1393-7.

13 Kuon Lee S, You YK, Park JH, et al. Single-port transumbilical laparoscopic cholecystectomy: a preliminary study in 37 patients with gallbladder disease. J Laparoendosc Adv Surg Tech A 2009;19(4):495-9.

14 Dubois F, Icard P, Berthelot G, et al. Coelioscopic cholecystectomy: preliminary report of 36 cases. Ann Surg 1990;211(1):60-2.

15 Litynski GS. Profiles in laparoscopy: mouret, dubois, and perissat: the laparoscopic breakthrough in Europe 1987 1988. JSLS 1999;3(2):163-7.

16 Lichten JB, Reid JJ, Zahalsky MP, et al. Laparoscopic cholecystectomy in the new millennium. Surg Endosc 2001;15(8):867-72. 
17 Poon CM, Chan KW, Lee DW, et al. Two-port versus fourport laparoscopic cholecystectomy. Surg Endosc 2003;17(10):1624-7.

18 Sarli L, Iusco D, Gobbi S, et al. Randomized clinical trial of laparoscopic cholecystectomy performed with miniinstruments. Br J Surg 2003;90(11):1345-8.
19 Pelosi MA, Pelosi MA. Laparoscopic appendectomy using a single umbilical puncture (minilaparoscopy). J Reprod Med 1992;37(7):588-94.

20 Bisgaard T, Klarskov B, Trap R, et al. Pain after microlaparoscopic cholecystectomy a randomized doubleblind controlled study. Surg Endosc 2000;14(4):340-4. 